\title{
COMPARATIVE POTENCIES AND $\beta_{2}$-ADRENOCEPTOR SELECTIVITIES OF RIMITEROL AND SALBUTAMOL AEROSOLS
}

Rimiterol hydrobromide, a $\beta$-adrenoceptor stimulating drug, is a member of a new series of sympathomimetic amines cyclized about the $\alpha$-carbon atom. Studies in man have demonstrated rimiterol to be an effective short-acting bronchodilator by the inhalational and parenteral routes of administration, with a high degree of $\beta_{2}$-adrenoceptor selectivity (Griffin \& Turner, 1971; Prime, Kamburoff \& Gunthner, 1971; Phillips, Woolnough, Marinova \& Turner, 1972; Svedmyr, Malmberg \& Thiringer, 1972; Griffin, Williams \& Maughan, 1973; Shenfield \& Paterson, 1973; Cooke, Kerr, Willey, Hoare, Grant \& Crompton, 1974; Evans, Shenfield, Thomas, Walker \& Paterson, 1974; Bianco, Kamburoff \& Prime, 1975; Marlin \& Turner, 1975a, b \& c). The object of this study was to compare by dose-response curves the bronchodilator potency and $\beta_{2}$-adrenoceptor selectivity of rimiterol and salbutamol by pressurized aerosol.

Six patients, aged 30-71 years, with chronic, partially reversible airways obstruction were chosen for this study. Their baseline forced expiratory volume in one second $\left(F E V_{1}\right)$ ranged between 26 and $55 \%$ of predicted normal and their $\% \mathrm{FEV}_{1}$ increase after $200 \mu \mathrm{g}$ salbutamol by pressurized aerosol between 20 and $88 \%$. The patients were receiving maintenance treatment with combinations of prednisone, theophylline, disodium cromoglycate, beclomethasone dipropionate and salbutamol by pressurized aerosol.

The trial was a randomized, balanced, singleblind design and was conducted in the morning on three separate days. The treatments were 1) rimiterol (Pulmadil), $250 \mu \mathrm{g} /$ inhalation, 2) salbutamol (Ventolin), $100 \mu \mathrm{g} /$ inhalation and 3) placebo, inactive propellant, all by pressurized aerosol. The three treatments were administered from different canisters under close supervision and every attempt was made to conceal their appearance. It was necessary for there to be less than $15 \%$ variation between control, baseline $\mathrm{FEV}_{1}$ values on the three trial days. All sympathomimetic and theophylline drugs were withdrawn for $12 \mathrm{~h}$ prior to each day, but corticosteroids and disodium cromoglycate were continued at their maintenance doses. The written consent of each patient was obtained.

Resting, baseline $\mathrm{FEV}_{1}$ readings (highest of three values as control) with a Vitilograph and heart rate with an electrocardiogram were recorded. One treatment inhalation was then administered, and $\mathrm{FEV}_{1}$ and heart rate measurements were repeated at $10 \mathrm{~min}$ intervals until no further FEV $_{1}$ improvement occurred. A second inhalation was given and the same procedure of $\mathrm{FEV}_{1}$ and heart rate recordings repeated. Similarly, in sequence 2,4 and 8 inhalations were taken. Thus, the cumulative doses were $1,2,4,8$ and 16 inhalations of each drug and placebo. The results were submitted to statistical analysis using the paired Student's $t$-test.

There was no significant difference between the control $\mathrm{FEV}_{1}$ values before rimiterol (mean \pm s.e. mean, $1.30 \pm 0.231$ ), salbutamol (mean \pm s.e. mean, $1.22 \pm 0.221$ ) and placebo treatments (mean \pm s.e. mean, $1.29 \pm 0.221$ ). The mean, peak $\% \mathrm{FEV}_{1}$ changes from control after all three treatments are graphed in Figure 1 . The $\%$ FEV $_{1}$ increases from control after all the doses of the drugs were significantly greater than those after placebo $(P<0.01)$. There was no significant difference between the ventilatory responses after 1,2 and 4 inhalations of each drug. However, the $\% \mathrm{FEV}_{1}$ increases after 8 and 16 inhalations of salbutamol were significantly greater than those after rimiterol $(P<0,05)$. The mean, peak heart rate changes from control after the cumulative doses of all the treatments are shown in Table 1. The heart rate responses after each drug did not differ significantly from placebo, nor was there a significant difference between the drugs. No sideeffects were reported by any patient throughout the study.

The value of establishing dose-response curves when comparing the potency and selectivity of $\beta$-adrenoceptor stimulating drugs has been well established (Warrell, Robertson, Newton Howes, Conolly, Paterson, Beilin \& Dollery, 1970;

Table 1 The mean heart rate changes from control (beats/min) for six patients with chronic, partially reversible airways obstruction after cumulative doses of $1,2,4,8$ and 16 inhalations of rimiterol, salbutamol and placebo by pressurized aerosol

$$
\begin{aligned}
& \text { Number of inhalations } \\
& \begin{array}{lllll}
1 & 2 & 4 & 8 & 16
\end{array}
\end{aligned}
$$

Drug Heart rate change from control (beats/min)

$$
\begin{array}{llllll}
\text { Rimiterol } & -1.8 & -3.0 & -5.5 & -4.7 & -0.5 \\
\text { Salbutamol } & +0.5 & -1.2 & -4.0 & -3.5 & +1.0 \\
\text { Placebo } & +0.1 & -0.8 & -1.8 & +0.3 & +0.7
\end{array}
$$




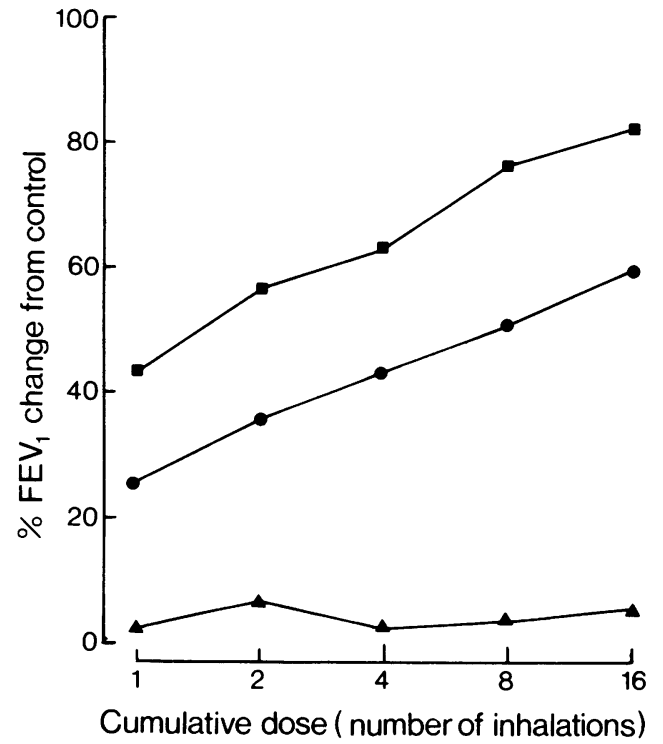

Figure 1 The log dose (number of inhalations)/response (\% FEV 1 change from control) curves for rimiterol ( $\bullet$ ), salbutamol ( $\triangle$ ) and placebo ( $\Delta$ ) by pressurized aerosol in six patients with chronic partially reversible airways obstruction. (One inhalation of rimiterol $=250 \mu \mathrm{g}$, of salbutamol $=100 \mu \mathrm{g}$.)

Svedmyr et al., 1972; Shenfield \& Paterson, 1973). For this purpose it is important to compare equimolar doses of drugs. The molecular weights of the active bases of rimiterol and salbutamol are 223 and 239 respectively. It was not technically possible to have the pressurized aerosols prepared to deliver these equimolar doses by a single inhalation for this study. Thus, approximately double the equimolar dose of rimiterol compared with salbutamol was used for each treatment. When the drugs were compared on an equimolar basis, salbutamol was approximately three and a half times more potent than rimiterol. Bianco et al. (1975) demonstrated that there was no significant difference in bronchodilatation with single doses of $500 \mu \mathrm{g}$ rimiterol and $200 \mu \mathrm{g}$ salbutamol by pressurized aerosol in asthmatic patients, although the peak effect was greater after salbutamol. Marlin \& Turner (1975a and b) showed that by the intravenous route salbutamol was about one and a half times more potent than rimiterol. This improvement in potency by the intravenous route compared to inhalation might be related to differences in the rate of uptake into tissues and metabolism by catechol-o-methyl transferase prior to its pharmacological effect on the bronchus. The heart rate changes after large cumulative doses of rimiterol and salbutamol were clinically negligible, demonstrating the wide margin of safety of both drugs.

In summary, rimiterol by pressurized aerosol possesses a high degree of $\beta_{2}$-adrenoceptor selectivity similar to salbutamol, but is less potent as a bronchodilator when compared on an equimolar basis. This study suggests that $350 \mu \mathrm{g}$ rimiterol would produce equivalent bronchodilatation to $100 \mu \mathrm{g}$ salbutamol.

\section{G.E. MARLIN, B.J.S. HARTNETT \& N. BEREND \\ Respiratory Unit, Repatriation General Hospital, Concord, N.S.W., 2139, Australia}

Received October 11, 1976

\section{References}

BIANCO, S., KAMBUROFF, P.L. \& PRIME, F.J. (1975). Comparison between the bronchodilator and cardiovascular effects of inhaling $0.5 \mathrm{mg}$ rimiterol (Pulmadil) and $0.2 \mathrm{mg}$ salbutamol. Curr. med. Res. Opin., 3, 30-35.

COOKE, N.J. KERR, J.A., WILLEY, R.F., HOARE, MARGARET V., GRANT, I.W.B. \& CROMPTON, G.K. (1974). Response to rimiterol and salbutamol aerosols administered by intermittent positive-pressure ventilation. Br. med. J., 1, 250-252.

EVANS, MARION E., SHENFIELD, GILLIAN M., THOMAS, N., WALKER, S.H. \& PATERSON, J.W. (1974). The pharmacokinetics of rimiterol in man. Xenobiotica, 4, 681-692.

GRIFFIN, J.P. \& TURNER, P. (1971). Preliminary studies of a new bronchodilator (WG 253) in man. $J$. clin. Pharmac., 11, 280-287.

GRIFFIN, J.P., WILLIAMS, J.R.B. \& MAUGHAN, ELIZABETH (1973). Studies in the human pharmacology and metabolism of rimiterol (Pulmadil), comparison with isoprenaline. Clin. Trials J., 10, 13-17.

MARLIN, G.E. \& TURNER, P. (1975a). Comparison of the $\beta_{2}$-adrenoceptor selectivity of rimiterol, salbutamol and isoprenaline by the intravenous route in man. Br. J. clin. Pharmac., 2, 41-48.

MARLIN, G.E. \& TURNER, P. (1975b). The relative potencies and $\beta_{2}$-selectivities of intravenous rimiterol, salbutamol and isoprenaline in asthmatic patients. Int. J. clin. Pharmac. Biopharm., 12, 158-169.

MARLIN, G.E. \& TURNER, P. (1975c). Intravenous therapy with rimiterol and salbutamol in asthma. $B r$. med. J., 2, 715-719.

PHILLIPS, EILEEN M., WOOLNOUGH, N., MARINOVA, VERA M. \& TURNER, P. (1972). A comparison of isoprenaline, salbutamol and rimiterol inhalation on skin temperature, heart rate and respiration in man. J. clin. Pharmac., 12, 158-168. 
PRIME, F.J., KAMBUROFF, P.L. \& GUNTHNER, W. (1971). Comparison of the bronchodilatory action of two drugs. Int. J. clin. Pharmac. Ther. Tox., 5, 293-295.

SHENFIELD, GILlIAN M. \& PATERSON, J.W. (1973). Clinical assessment of bronchodilator drugs delivered by aerosol. Thorax, 28, 124-128.

SVEDMYR, N., MALMBERG, R. \& THIRINGER, G. (1972). The effect of a new adrenergic beta ${ }_{2}$ - receptor-stimulating agent (rimiterol, $\mathbf{R 7 9 8 ) ~ i n ~}$ patients with chronic obstructive lung disease. Scand. J. resp. Dis., 53, 302-313.

WARRELL, D.A., ROBERTSON, D.G., NEWTON HOWES, J., CONOLLY, M.E., PATERSON, J.W., BEILIN, L.J. \& DOLLERY, C.T. (1970). Comparison of cardiorespiratory effects of isoprenaline and salbutamol in patients with bronchial asthma. $\mathrm{Br}$. med. $\mathrm{J}$., 1, 65-70.

\section{STUDIES OF THE EFFECT OF THYROID DYSFUNCTION ON THE ELIMINATION OF $\beta$-ADRENOCEPTOR BLOCKING DRUGS}

It is now clearly recognised that drug metabolism may be altered by disease. Hence renal disease may effect drug clearance through its influence on elimination or on plasma binding. Thyroid dysfunction has also been shown to alter the metabolism of several drugs. The elimination half-life of antipyrine is shortened in hyperthyroid subjects and prolonged in hypothyroid subjects (Crooks, Headley, McNee \& Stevenson, 1973; Vesell \& Passananti, 1973; Eichelbaum, Bodem, Gugler, Schneider-Deters \& Dengler, 1974): the plasma concentrations and serum half-lives of digoxin have been shown to be lower in hyperthyroid and higher in hypothyroid patients apparently related to changes in creatinine clearance (Croxson \& Ibbertson, 1975). However, recently the apparent half-life and other pharmacokinetic parameters of propylthiouracil in ten hyperthyroid subjects were not found significantly different from corresponding values in a previous study in euthyroid subjects (Kampmann \& Skovsted, 1974; Kampmann \& Skovsted, 1975).

In the past few years, the use of $\beta$-adrenoceptor blocking drugs, particularly propranolol, has become established in various aspects of the management of hyperthyroidism (Turner, 1974; McDevitt, 1976). No information is currently available on the influence of thyroid disease on the metabolism of $\beta$-adrenoceptor blocking drugs. We have, therefore, studied the elimination of propranolol and practolol, two drugs with different modes of clearance (Shand, 1974), in patients both with hyperthyroidism and hypothyroidism.

Eight patients with hyperthyroidism and four with hypothyroidism have been studied. Their age, sex and biochemical findings are shown in Table 1 . Patients with heart disease, bronchial asthma and hepatic or renal disease were excluded. After an overnight fast, each patient was given propranolol $(100 \mathrm{mg})$ orally at $09.00 \mathrm{~h}$ on Day 1 and practolol $(400 \mathrm{mg}$ ) orally at $09.00 \mathrm{~h}$ on Day 2 . The order of drug administration was not randomised due to the longer half-life of practolol and the need to have patients in hospital for as brief a time as possible. Blood samples were withdrawn through an indwelling catheter in a forearm vein. With propranolol, blood samples were withdrawn before and at $1,2,3,4,6,9$ and $12 \mathrm{~h}$ after the drug was given: samples were heparinised. Blood samples for practolol were withdrawn before and at $1,2,3,5$, $7,9,12,24,36$ and $48 \mathrm{~h}$ after drug administration. Blood samples for practolol were oxalated. Plasma propranolol concentrations were subsequently measured by the standard spectrofluorometric method (Shand, Nuckolls \& Oates, 1970) and blood practolol concentrations by a

Table 1 Mean \pm s.e. mean observations on eight patients with hyperthyroidism and four patients with hypothyroidism

\begin{tabular}{llrrrrr} 
Thyroid status & \multicolumn{1}{c}{ Sex } & Age (years) & $\begin{array}{c}T_{3}^{*} \\
\text { (\% uptake) }\end{array}$ & $\begin{array}{c}T_{4}^{+} \\
\text {(mmol/I) }\end{array}$ & F.T.I.t \\
Hyperthyroid & 7F, 1M & $50.8 \pm 4.8$ & $85.9 \pm 4.5$ & $234.5 \pm 18.3$ & $280.1 \pm 31.1$ \\
Hypothyroid & 4F & $48.0 \pm 6.5$ & $127.4 \pm 1.1$ & $21.1 \pm 8.0$ & $17.5 \pm 5.8$
\end{tabular}

- Normal range, 95-122\% uptake; + Normal range, 54.1-144.1 mmol/l; + Normal range, 51.5-141.6 